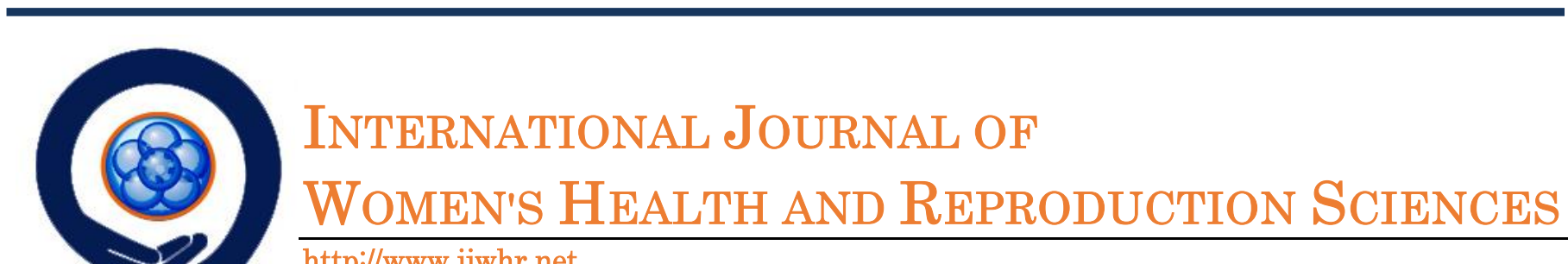

http://www.ijwhr.net

doi: 10.15296/ijwhr.2013.08

\title{
Improvement Effect of Rosmarinic Acid on Serum Testosterone Level after Exposing with Electromagnetic Fields
}

\author{
Arezoo Farsi ${ }^{1}$, Arash Khaki ${ }^{2}$, Fatemeh Fathiazad ${ }^{3}$, Fatemeh Afshari ${ }^{4}$, Laleh Hajhossini ${ }^{5}$, \\ Amir Afshin Kahki6
}

\section{Article History: \\ Received April 2013 \\ Accepted May 2013 \\ Keywords: \\ EMF \\ Rosmarinic acid \\ Testosterone.}

Available online July 2013

\section{Corresponding Author:}

Arash khaki, Women's

Reproductive Health Research

Center, Tabriz University of

Medical Sciences, Tabriz, Iran.

Tel: +984115541221

Email: arashkhaki@yahoo.com

\begin{abstract}
Objective: Rosmarinic acid has antioxidant, anti-inflammatory and antimicrobial activities and helps to prevent cell damage caused by free radicals and other sources.

Material and Methods: Male Wistar rats $(n=40)$ were allocated to four groups, a control group $(n=10)$ and three treatment groups $(\mathrm{n}=30)$. The first treatment group received rosmarinic acid ( $5 \mathrm{mg} / \mathrm{kg}$ body weight) by gavage method, the second test group received rosmarinic acid $(5 \mathrm{mg} / \mathrm{kg}$ body weight) by gavage and electromagnetic field (EMF) exposure at $50 \mathrm{~Hz}$ for 42 consecutive days, whilst the third test group just received EMF exposure for 42 consecutive days respectively; however, control group received 5cc Normal saline $(0.9 \% \mathrm{NaCl})$ daily by gavage method.

Results: In 42nd day of research, 5 cc blood was collected for testosterone level measurement from whole groups. The level of testosterone significantly increased in groups that received Rosmarinic acid $(\mathrm{P}<0.05)$.

Conclusion: Since in our study administration of $5 \mathrm{mg} / \mathrm{kg}$ Rosmarinic acid significantly have increasing effect on decreased testosterone that is caused by EMF, it seems that using Rosmarinic acid as food additive can be efficient for supporting people living in EMF environmental pollution.
\end{abstract}

1. Faculty of Medicine,Tabriz Branch,Islamic Azad University,Tabriz-Iran.

2. Women's Reproductive Health Research Center, Tabriz University of Medical Sciences, Tabriz, Iran.

3. Department of Pharmacognosy, Tabriz University of medical sciences, Tabriz-Iran.

4. Department of Histopathology, Tabriz Branch, Islamic Azad University, Tabriz, Iran.

5. Department of Food and Nutrition Science, San Jose State University, CA, USA.

6. Department of Anatomical sciences, Tabriz University of medical sciences, Tabriz-Iran 


\section{Introduction:}

Testosterone is a hormone from the androgen group and is found in mammals, fowl, rodents and vertebrates. In males, testosterone is primarily secreted in the testicles although small amounts are also secreted by the adrenal glands. It is the principal male sex hormone and an anabolic steroid (1) Rosmarinic acid (R.A) belongs to the group of polyphenols that are strong antioxidants that complement the functions of antioxidant vitamins and enzymes as a defense against oxidative stress caused by excess reactive oxygen species (ROS) (2). Many studies have shown that Rosemary extracts play important roles as antiinflammation, antitumor, and antiproliferation in various in vitro and in vivo settings (3). Rosemary extracts have been used as an antioxidant to improve fertility and sperm quality (4). A few studies have suggested the involvement of lipid peroxidation and free radical formation (5), as well as biochemically induced oxidative stress. Many studies by khaki et al Showed that EMF has harmful side effects on sexual hormones ,reproductive organs in mammals and could be baneful on spermatogenesis $(6,7)$. Antioxidants secreted by the reproductive tract protect spermatozoa against the toxic effects of reactive oxygen species (ROS) after ejaculation (8). Vitamin $\mathrm{E}$ can regulate apoptosis-related protein $\mathrm{Bcl}-2$, Bax expression and confront free radical damage which in turn contributes to a protective effect in ovarian cells (9). Previous studies have shown that the extract of Rosemary leaves known as antioxidant belongs to the group of polyphenols (1). The aim of this study was to see antioxidant effect of Rosmarinic acid on modulating of serum testosterone level after exposure with electromagnetic fields (EMF) in Rats.

\section{Material \& Methods:}

\section{Animals}

Forty adult male Wistar rats with weight of $250 \pm 10 \mathrm{~g}$ were maintained for one week before use in this study. Rats were housed together (10 per cage) and fed on a compact diet in the form of granules and water. The diet contained all the essential ingredients, including vitamins and minerals. The environmental conditions (temperature and humidity) in all the animal keeping areas were continuously monitored. Temperature was maintained at $23^{\circ} \mathrm{C}$ and humidity was maintained at 35 to $60 \%$. Light was provided on a $12 \mathrm{~h}$ light/dark cycle from 0700 to $1900 \mathrm{~h}$. All animals were treated in accordance to the Principles of Laboratory Animal Care (NIH) throughout the study. The experimental protocol was approved by the Animal Ethics Committee in accordance with the guide for the care and use of laboratory animals prepared by Tabriz University of Medical Sciences. Rats were allocated randomly to four groups, a control group $(\mathrm{n}=10)$ that received $5 \mathrm{cc}$ of Normal saline $(0.9 \%)$ daily by gavage method and three treatment groups (total $=30$ ) and $n=$ 10 in each group. The first treatment group received rosmarinic acid $(5 \mathrm{mg} / \mathrm{kg})$, the second test group received rosmarinic acid (5 mg/kg body weight) and EMF exposure at $50 \mathrm{~Hz}$ for 42 consecutive days, while the third treat group just received EMF exposure for 42 consecutive days. Animals were maintained under standard conditions with respect to humidity, illumination and temperature for 42 consecutive days.

\section{Pharmacological Procedure :}

Rosmarinic acid was purchased from Sigma Chemicals (St. Louis, Mo., USA). Rosmarinic acid was dissolved in normal saline(0.9\%) $(5 \mathrm{mg} / \mathrm{kg})$ administered by gavage.

\section{EMF-producing system :}

The equipment was based on the Helmholtz coil, which operated following Fleming's right hand rule. The equipment produced an alternating current of $50 \mathrm{~Hz}$, which created an EMF of $80 \mathrm{G}$. The intensity of the EMF was controlled using a transformer. The equipment had two main parts. In the first part, there were two copper coils that were placed, one above the other and separated by a distance of $50 \mathrm{~cm}$. A cylindrical wooden vessel was placed between the coils (the exposure area), the interior of which contained a chamber for holding the caged experimental animals. The second part was the transformer, which 
controlled the input and output voltage using a voltmeter and the current with an ampere meter. A fan was used as required, to prevent increase in temperature inside the chamber. Four cages at a time were placed within the chamber, with ten rats per cage.

Measurement of Total Serum Testosterone Hormone :

Total serum concentration of testosterone was measured using a double-antibody RIA kit (Immunotech Beckman Coulter Co., USA). The testosterone detection sensitivity per assay tube was $0.025 \mathrm{ng} / \mathrm{ml}$

Statistical analysis :

Statistical analysis was done using the ANOVA and test for comparison of data in the control group with the experimental groups. The results were expressed as mean \pm S.E.M (standard error of means). P-value less than 0.05 were considered significant and were written in the parentheses.

\section{Results:}

Result of Testosterone levels :

Testosterone level in EMF group was $(0.75 \pm 0.05)$, in R.A group was (4.1 \pm 0.05$)$, in R.A+EMF group was $(3 \pm 0.05)$ and in control group was $(2.2 \pm 0.05) \mathrm{ng} / \mathrm{ml}$ respectively. These changes were significant as $\mathrm{P}$-value less than 0.05 $(\mathrm{P}<0.05)$. Statistical analysis Dunnett (one side) shows significant differences among experimental groups in comparison to control group $(\mathrm{P}<0.05)$, (Table 1$)$.

\section{Discussion:}

Many researches and studies confirmed that when testosterone in ejaculated semen contact the cervical wall after sexual intercourse, females receive a spike in testosterone, endorphin, and oxytocin levels, and males after orgasm during copulation experience receive increase in endorphins and a marked increase in oxytocin level. Researchers on rats have indicated that degree of their sexual arousal is sensitive to reduction in testosterone level. When testosterone-deprived rats were given medium levels of testosterone, their sexual behaviors (copulation, partner preference, etc.) were resumed while this result was not seen when they were given low amounts of the same hormone (10). LH (luteinizing hormone) plays a pivotal role in the control of LC (Leydig cell) development; during normal puberty, testosterone biosynthesis is dependent on the stimulation of testicular Leydig cells through activation of the LH receptor (LHR) by LH and the placental LH homolog, human chorionic gonadotropin (hCG). The increased use of power lines and modern electrical devices cause public health hazards; Exposure to EMF has adverse effects on spermatogenesis by the Sertoli and Leydig cells, so chronic exposure to EMF has attracted considerable attentions(11).Magnetic fields of $50 \mathrm{~Hz}$ also induce cytotoxic and cytostatic changes in the spermatogonial differentiation of mice (5). EMF is able to generate destructive reactive oxygen species, including superoxide, hydrogen peroxide and hydroxyl radical leading to oxidative and necrotic damages (6).Our results revealed that $50 \mathrm{~Hz}$ EMF may decrease testosterone level while Rosmarinic acid may modulate the testosterone level in rats after receiving EMF.

These results are also consistent with other results of some studies in this area $(7,12)$. In the last few years, a great deal of interest has been particularly showed to phenolic compounds among the major classes of phytochemical antioxidants existing in fruits and vegetables. Dietary polyphenols have received tremendous attention among nutritionists, food scientists and consumers due to their roles in human health. Researches in recent years strongly support a role of polyphenols in the preventing degenerative diseases, particularly cancers, cardiovascular diseases and neurodegenerative diseases (13). In addition to the above possible mode of antioxidant actions, other mechanisms such as inhibition of xanthine oxidase and elevation of endogenous antioxidants are also considered important (14). The in vitro capacity of polyphenols to act as both primary and secondary antioxidants has been probably the best described property of almost every group of flavonoid and nonflavonoid compounds; however, this concept appears now to be an oversimplified view of their mode of action 
(12). In fact, it is suggested a variety of other potential mechanisms of action of polyphenols in cells and protection against oxidative stress. In our results, this herb could show beneficial role by increasing in serum testosterone, so we can conclude that these benefits are related to Ros-A, antioxidants' effects and its flavonoid that could have useful effects on sex hormones and increasing of sperms population (11, 12 , 15). There are also prior confirmed studies about the effect of polyphenols of Ros-A on the proliferation and apoptosis of activated hepatic stellate cells (HSC-T6); it has been shown R.A has beneficial effects on apoptosis and protection against hepatic cell damage (16). A better understanding of underlying mechanisms in fertility and better study results clarifying the effectiveness of nutritional and biochemical factors are important to improve diagnosis and treatment. These effects may result in the increase of Leydig cells proliferation in the EMF group, so it will be suggested that using Rosmarinic acid has beneficial effect on improvement of serum testosterone in population that involve with radiation waves such as electric power .

\section{Conflict of interest statement}

We declare that we have no conflict of interest.

\section{Acknowledgments:}

This research was done by research grand: 9029, approved in 2011 belong to Women's Reproductive Health Research Center, Tabriz University of Medical Sciences, Tabriz, Iran. We gratefully thank for their help and financial support.

Table-1: Testosterone levels of rats exposed to $50 \mathrm{~Hz}$ electromagnetic fields and $5 \mathrm{mg} / \mathrm{kg}$ Rosmarinic acid

\begin{tabular}{ccccc}
\hline Groups & $\begin{array}{c}\text { Control } \\
\text { Normal saline } \\
(\mathbf{0 . 9 \%} \mathbf{~ N a C l})\end{array}$ & $\begin{array}{c}\text { Rosmarinic acid } \\
(\mathbf{5 m g} / \mathbf{k g})\end{array}$ & $\begin{array}{c}\text { Electromagnetic } \\
\text { field } \\
\mathbf{( 5 0 H z )}\end{array}$ & $\begin{array}{c}\text { Electromagnetic field } \\
(50 \mathrm{~Hz}) \text { with Rosmarinic } \\
\text { acid } \\
(\mathbf{5 m g} / \mathbf{k g})\end{array}$ \\
\hline Testosterone $(\mathbf{n g} / \mathrm{ml})$ & $2.2 \pm 0.05$ & $4.1 \pm 0.05^{*}$ & $0.75 \pm 0.05^{*}$ & $\mathbf{3 \pm 0 . 0 5}$ \\
\hline
\end{tabular}




\section{References:}

1. Tarulli GA, Stanton PG, Loveland KL, Meyts ER, McLachlan RI, Meachem SJ. A survey of Sertoli cell differentiation in men after gonadotropin suppression and in testicular cancer. Spermatogenesis 2013; 3(1):e24014.

2. Kuo CF, Su JD, Chiu CH, Peng CC, Chang CH, Sung TY, et al. Anti-Inflammatory Effects of Supercritical Carbon Dioxide Extract and Its Isolated Carnosic Acid from Rosmarinusofficinalis Leaves. J Agric Food Chem 2011; 59(8): 3674-85.

3.Cheng AC, Lee MF, Tsai ML, Lai CS, Lee JH, Ho CT, et al. Rosmanol potently induces apoptosis through both the mitochondrial apoptotic pathway and death receptor pathway in human colon adenocarcinoma COLO 205 cells. Food Chem Toxicol 2011; 49(2): 485-93.

4. Malo C, Gil L, Gonzalez N, Martínez F, Cano R, de Blas I, et al. Anti-oxidant supplementation improves boar sperm characteristics and fertility after cryopreservation: comparison between cysteine and rosemary (Rosmarinus officinalis). Cryobiology. 2010; 61(1): 142-7.

5. Khaki AA, Zarrintan S, Khaki A, Zahedi A. The effects of electromagnetic field on the microstructure of seminal vesicles in rat: a light and transmission electron microscope study. Pak J Biol Sci 2008; 11(5):692-701.

6. Khaki A, Fathiazad F, Nouri M, Khaki AA, Maleki NA, Khamnei HJ, et al. Beneficial effects of quercetin on sperm parameters in streptozotocin-induced diabetic male rats. Phytother Res 2010;24(9):1285-91.

7. Khaki A, Fathiazad F, Nouri M, Khaki AA. Effect of Ocimum basilicum on apoptosis in testis of rats after exposure to electromagnetic field. AJPP 2011; 5(12): 1534-1537.

8. Koziorowska-Gilun M, Koziorowski M, Fraser L, Strzeżek J. Antioxidant defence system of boar caudaepididymidal spermatozoa and reproductive tract fluids. Reprod Domest Anim 2011; 46(3):527-33.

9. Lu CZ, Shi YH, Jiao RS, Kong YK, Yao LC. Study on protective effect of vitamin E for ovarian grandlose cells and its mechanism in aged rats. Zhongguo Ying Yong Sheng Li Xue Za Zhi. 2009; 25(4): 565-8.

10.Gray PB, Chapman JF, Burnham TC, McIntyre MH, Lipson SF, Ellison PT .Human male pair bonding and testosterone. Human Nature. 2004; 15 (2): 119-131.

11. Martínez-Sámano J, Torres-Durán PV, Juárez-Oropeza MA, Elías-Viñas D, VerdugoDíaz L. Effects of acute electromagnetic field exposure and movement restraint on antioxidant system in liver, heart, kidney and plasma of Wistar rats: a preliminary report. Int J Radiat Biol 2010; 86(12): 1088-94 
12. Limón-Pacheco J, Gonsebatt ME. The role of antioxidants and antioxidant-related enzymes in protective responses to environmentally induced oxidative stress. Mutat Res. 2009; 674(1-2): 137-147.

13. Khaki A, Farnam A, Davatgar Badie A, Nikniaz H. Treatment Effects of Onion (Allium cepa) and Ginger (Zingiber officinale) on Sexual Behavior of Rat after Inducing an Antiepileptic Drug (lamotrigine). Balkan Med J. 2012; 29( 3): 236-242.

14.Cuerda C, Luengo LM, Valero MA, Vidal A, Burgos R, Calvo FL, et al. Antioxidants and diabetes mellitus: review of the evidence. Nutr Hosp 2011; 26(1): 68-78.

15.Khaki A, Imani SAM, Golzar F. Effects of rosmarinic acid on male sex hormones (testosterone-FSH-LH) and testis tissue apoptosis after exposure to electromagnetic field (EMF) in rats. African Journal of Pharmacy and Pharmacology 2012; 6(4): 248-252.

16.Zhang JJ, Wang YL, Feng XB, Song XD, Liu WB. Rosmarinic acid inhibits proliferation and induces apoptosis of hepatic stellate cells. China Biol Pharm Bull 2011; 34(3): 343-8. 